John Urry et Jonas Larsen, The Tourist Gaze 3.0

Sage, 2011, 280 pages

\title{
Mathis Stock
}

\section{OpenEdition \\ Journals}

Édition électronique

URL : http://journals.openedition.org/tourisme/201

DOI : 10.4000/tourisme.201

ISSN : 2492-7503

Éditeur

Éditions touristiques européennes

\section{Édition imprimée}

Date de publication : 1 juin 2013

Pagination : 105-106

ISSN : 2109-5671

\section{Référence électronique}

Mathis Stock, « John Urry et Jonas Larsen, The Tourist Gaze 3.0 », Mondes du Tourisme [En ligne], 7| 2013, mis en ligne le 30 septembre 2015, consulté le 22 septembre 2020. URL : http:// journals.openedition.org/tourisme/201 ; DOI : https://doi.org/10.4000/tourisme.201

Ce document a été généré automatiquement le 22 septembre 2020.

\section{$\Theta \Theta \Theta \Theta$}

Mondes du tourisme est mis à disposition selon les termes de la licence Creative Commons Attribution - Pas d'Utilisation Commerciale - Pas de Modification 4.0 International. 


\title{
Lectures critiques
}

\section{John Urry et Jonas Larsen, The Tourist Gaze 3.0}

Sage, 2011, 280 pages

\author{
Mathis Stock
}

\section{RÉFÉRENCE}

John Urry et Jonas Larsen, The Tourist Gaze 3.0, Sage, 2011.

1 Vingt ans après sa première édition, The Tourist Gaze [littéralement, "le regard fixe du touriste" ou "le regard touristique"], l'ouvrage qui a modifié en profondeur la façon dont les sciences sociales appréhendent le phénomène touristique et qui est parmi les plus cités par les différentes approches scientifiques du tourisme, fait le fruit d'une nouvelle édition, entièrement remise à jour.

2 Avec Jonas Larsen comme co-auteur de cette troisième édition, John Urry s'est assuré de la collaboration d'un sociologue qui a travaillé sur la question de la performance et du lien avec la spatialité du tourisme. Cet ouvrage réussit-il la gageure d'être encore actuel vingt ans après sa première édition ? Arrive-t-il à synthétiser les débats et les avancées théoriques, méthodologiques et empiriques qui ont eu lieu depuis? D'emblée, le lecteur est impressionné par la somme des travaux, publiés dans les années 1990 et 2000, que les auteurs ont réussi à mobiliser pour modifier en profondeur le contenu de l'édition précédente. Un regret : une bibliographie exclusivement anglophone, l'appel de Löfgren (1999) pour une prise en compte des travaux d'autres langues n'ayant pas été entendu. Le style de l'ouvrage, quant à lui, est peu homogène, oscillant entre des synthèses de type essai et article scientifique.

Les chapitres suivants structurent cet ouvrage : le chapitre "Theories" discute la notion de "tourist gaze"; "Mass Tourism" raconte l'avènement des stations balnéaires britanniques; "Economies" met en place une compréhension des enjeux de l'industrie touristique, "Working under the Gaze" traite du problème du travail et de l'emploi ; “ 
Changing Tourist Cultures" discute des différentes façons de faire du tourisme; "Places, Buildings and Design" se focalise sur les lieux touristiques; "Vision and Photography" reconstruit l'importance de la photographie depuis le xIxe siècle pour le regard touristique; "Performances" ausculte les multiples pratiques touristiques; enfin, "Risks and Futures" tente d'imaginer les enjeux futurs du tourisme. On peut se poser la question de la manière dont la sélection des thèmes traités a été effectuée. La question de l'altérité se trouve évacuée, celle de la mobilité est sous-développée.

Il y a vingt ans, la notion de "regard touristique" a permis de comprendre comment un nouveau rapport au monde est à l'œuvre à partir du visuel. Aujourd'hui, les auteurs font le constat d'un "globalising of the tourist gaze" (p. 30): "There has thus been a major shift from a limited range of tourist gazes in the nineteenth century to the proliferation of discourses, forms and embodiments of tourist gazes now" (p.30) [On a assisté à un changement majeur, passant d'un nombre limité de regards touristiques au xix ${ }^{e}$ siècle à la multiplicité des discours, des formes et des incarnations de regards touristiques aujourd'hui]. Ce constat, qui fait écho à celui du "genre commun du tourisme" (Lussault, 2007) et du "tournant re-créatif" (Équipe Mit, 2011), permet de positionner d'une nouvelle façon l'objet "tourisme". Le chapitre "Theories", qui discute notamment de la notion de "tourist gaze", répond partiellement aux critiques émises depuis vingt ans et précise la notion : le livre "rethinks the concept of the tourist gaze as performative, embodied practices, highlighting how each gaze depends upon practices and material relations as upon discourses and signs" (pp.14-15) [repense le concept de regards touristiques en tant que pratiques performatives concrètes, soulignant que chaque regard dépend tant de pratiques et de relations matérielles que de discours et de signes]. Si le débat est passionnant, il manque cependant une contextualisation conceptuelle plus poussée, à la fois dans les sociologies du loisir (les réflexions d'Elias et Dunning sur le "quest for excitement" [la recherche d'excitation] ne sont pas intégrées) et du point de vue de la social theory. On aurait pu s'attendre aussi à une discussion plus approfondie des avancées conceptuelles en tourism studies. L'ambition qui vise à "summarize the seminal contributions to the sociology of tourism" (p. 7) [résumer les contributions fondamentales à la sociologie du tourisme] n'est pas remplie. Trois questions notamment sont absentes : comment avons-nous appris à être touriste, comment le tourist gaze est-il appris et retransmis? Comment les lieux autres posent-ils problème pour les touristes, en tant que personnes en dé-placement? Comment fonctionne le système mondial de production d'attractions touristiques?

5 Les chapitres "Vision and Photography" et "Performances" sont les plus forts et les plus intéressants, car il s'agit de textes bien balisés, avec de multiples renvois théoriques et des développements empiriques passionnants. La "digitalité" des sociétés contemporaines est appréhendée comme enjeu central pour le tourisme, c'est là en effet que les changements les plus notables ont lieu. L'évolution de la photographie fait le lien avec la définition de "regard touristique"; elle fait comprendre l'importance de ce média depuis le XIX ${ }^{e}$ siècle. Dans "Performances", la question des mises en scène des pratiques touristiques est prise au sérieux; y sont notamment montrées les distances au rôle et l'importance des "techniques du corps". Les descriptions et interprétations sont convaincantes. On pourrait s'interroger sur la cohérence théorique : puisqu'on parle de pratiques - "ontologies of doing and acting" (p. 191) -, pourquoi les multiples angles d'approche de la pratique en sciences sociales ne sont pas mobilisés? Pourquoi ce rétrécissement sur Goffman, alors que les contributions sur les pratiques sont 
aujourd'hui légion, que l'on parle même d'un "practice turn" [tournant pratique] en sciences sociales (Knorr-Cetina et al., 2000)?

6 Le chapitre sur les "changing tourist cultures" est décevant. Les éléments construisant les différentes cultures n'y sont pas définies : qu'est-ce qu'une culture touristique? Une culture touristique se définit-elle à l'échelle nationale, régionale, locale ou bien en termes de "classe" ou de "style de vie" ? S'agit-il de "global practice communities" [communautés mondiales de pratique]? Les différentes manières d'être touriste n'y sont pas montrées. Le seul argument développé est celui d'un tourisme post-fordiste ou post-moderne. Une réflexion sur le lien entre pratiques touristiques et cultures de mobilité aurait permis de questionner les cultures touristiques actuelles: quelle conséquence sur les cultures touristiques si la mobilité et la pratique des lieux autres deviennent banales ? Là aussi, la mobilisation des théories des pratiques aurait permis d'aller plus loin et d'identifier de multiples cultures touristiques.

7 Le chapitre "Places" manque également d'approfondissement: du point de vue de la géographie, c'est là une des limites de la sociologie ! Je suis d'accord avec les auteurs pour dire que les touristes mobilisent de multiples façons les lieux avec lesquels ils s'engagent. Mais on pourrait poser la question de savoir comment ces lieux façonnent les pratiques. On pourrait aussi regretter que la production des lieux touristiques par le tourist gaze soit traitée uniquement comme un problème de design et de sites (musées, parcs à thème, etc.). La question plus fondamentale du comment on procède pour inventer des lieux touristiques (et pour quels touristes?), processus continu depuis 200 ans, n'est pas appréhendé.

En conclusion, un livre avec des apports significatifs qui n'existent pas comme tels ailleurs, mais avec certaines faiblesses de construction : peut-être à remédier pour la version 4.0 ?

\section{BIBLIOGRAPHIE}

Orvar LÖFGREN, On Holiday. A History of Vacationing, University of California Press, 1999.

Équipe MIT, Tourismes 3. La révolution durable, Belin, 2011.

Michel Lussault, "Le tourisme, un genre commun", dans Philippe Duhamel et Rémy Knafou (dir.), Mondes urbains du tourisme, Belin, 2007.

Karin KNORR CETINA, Theodore SCHATZKI et Eike VON SAVIGNY, The Practice Turn in Contemporary Theory, Routledge, 2001.

\section{AUTEURS}

\section{MATHIS STOCK}

Institut universitaire Kurt Bösch (IUKB) 